\title{
GROUNDWATER MONITORING USING GRACE MISSION
}

\author{
M. Shukla ${ }^{1}$, V. Maurya ${ }^{1}$, R. Dwivedi ${ }^{2 *}$ \\ ${ }^{1}$ GIS Cell, MNNIT Allahabad, Prayagraj, India- (mhtzs2801, vipinmaurya2010)@ gmail.com \\ ${ }^{2}$ GIS Cell, MNNIT Allahabad, Prayagraj, India- ramjid@mnnit.ac.in
}

KEY WORDS: GRACE, Groundwater, Water Crisis, Water Equivalent Height, Groundwater Monitoring.

\begin{abstract}
:
Since last few decades, India has met to major crises related to groundwater. Major cities, for example, Delhi, Chennai, Bengaluru etc. are facing extreme risk of water crisis. In next few decades, this may lead to a major water crisis when this non-renewable resource is exhausted. Gravity Recovery and Climate Experiment (GRACE) mission, widely used for monitoring of groundwater storage change, could be utilized to get the information of exact amount of water above or below the surface of the earth that may be used to counter act over such situation of water crisis. GRACE mission consists of two earth orbiting satellite vehicles (SVs) separated by $220 \mathrm{~km}$ with the objective of computing change in gravity by increasing or decreasing distance between both the SVs caused by higher or lower gravity masses. The primary objective of the presented work is to obtain the liquid water equivalent height in a selected area using GRACE mission data with GLDAS soil moisture data. The advantage of using GRACE is that it provides better accuracy (fraction of $1 \mathrm{~cm}$ ) in comparison to traditional methods, therefore, larger extent could be covered. This paper extensively discusses about GRACE application (especially groundwater monitoring), challenges with GRACE missions and about effective methods for groundwater recharge.
\end{abstract}

\section{INTRODUCTION}

During the last two-three decades, the water level in the whole world is gradually decreasing, which can cause huge crises all over the world. Major cities, for example, Delhi, Chennai, Bengaluru etc. are facing extreme risk of water crisis which may lead to a major water crisis when this non-renewable resource is exhausted. Various remote sensing techniques are used to locate $\&$ monitor water level and recharge them to a possible extinct, such as ERT profiles (using electrical resistance for sub-surface imaging), SD100 Ultrasonic Sensor (measuring water levels remotely), OTT-CBS (a bubbler) etc. Satellite Images used to aid in hydrological interpretation are widely rich in history. Recently, measurements by satellite of temperature, soils, topography, gravity, etc have been collected to detect the presence of groundwater. Satellite imagery is a part of larger probe where critical hydrological parameters have been directly measured from satellite data.

Unfortunately in older times the groundwater monitoring was very difficult globally, but in current scenario, we have enough remote sensing methods and equipment. In remote sensing techniques, GRACE data has been widely used for ground water monitoring purpose, in correcting gravity models and reducing correlation errors between two hydrological datasets (Becker, 2006, Chen et al., 2010; Houborg, 2012; Jiang et al., 2014; Landerer et al., 2013; Skaskevych, 2014; Syed et al,. 2008; Tian et al., 2017; Wang et al., 2013; Wouters et al. 2014; Yeh et al., 2006). The GRACE mission, launched in March 2002, consist of two twin satellites measures earth gravity changes with a very high accuracy (Tapley et al., 2004). GRACE tracks the variations in the distance between its twin satellites and combine the measurement with GPS receivers and accelerometers data. Hence, monthly gravity field variations data are obtained (Almeida et al. 2012). The Grace-based TWS application modifies data based primarily on a combination of hydrological and terrain models. Jiang et al. (2014) provides an extensive review of GRACE mission, its fundamental concept and its application in terrestrial hydrology, for example, terretsrial water storage and drought monitoring. The results of the Grace-based TWS restoration provide a local and temporal distribution of vertically integrated water supplies (surface water, soil, groundwater, and ice) in large river valleys. Thus, due to errors, the use of proxies may be reduced in some hydrological models such as discharge and variability.

Rodell and Famiglietti (2002) shows the application of GRACE data in ground water storage monitoring and concludes to the uncertainty of $\sim 8.7 \mathrm{~mm}$ in estimates of ground water by GRACE observation for high plains aquifer. Byron et al. (2004) presents the application of GRACE data in measuring temporal variations in geoid and discusses potential factors and possible errors in GRACE estimates. Wahr et al. (2006) presents accuracy assessment of mass variability maps obtained by GRACE by proposed method of estimation of error estimates. Swenson et al. (2006) conducts a study to estimate temporal variations in water storage by using GRACE data and finds the results are congruent with the field observations. Strassberg et al. (2007) presents the potential of GRACE data in monitoring seasonal ground water storage in semiarid regions by comparing ground water results obtained by GRACE and field data. Rodell et al. (2009) shows the efficacy of data obtained by GRACE mission and find ground water to be depleting at rate of $40 \pm 10$ mm/year (mean value) for Rajasthan, Delhi, Punjab and Haryana states of India.

Chen et al. (2016) quantify change in ground water storage using GRACE data for selected places in the world facing water

\footnotetext{
* Corresponding author
} 
scarcity. Bhanja et al. (2016) validates anomalies in ground water storage obtained by GRACE with observations of more than 15000 wells spread in India. Chen et al. (2019) utilizes GRACE data to obtain variation of ground water storage and analyses its effects on occurrence of flood and drought. Feng (2019) developed a matlab toolbox, named GRAMAT, for dedicated GRACE data processing and generated map of monthly terrestrial water storage change for Amazon river. Singh and Saravanan (2020) presents a study of improving ground water monitoring for various simple and complex aquifers using GRACE data and conducted a correlation analysis between actual and GRACE estimates. The main limitation of GRACE data is availability of data with very low resolution $\left(0.25^{\circ}\right.$ and $\left.1^{\circ}\right)$ which limits its application for ground water monitoring at small scale.

The primary objective of the research work is to obtain temporal change in water equivalent height of Allahabad district of India using GRACE mission data with GLDAS soil moisture data.

\section{STUDY AREA}

The selected study area for this research is Allahabad, a district of Uttar Pradesh state of India (Figure 1). Allahabad is a metropolice city ranking at top in population in Uttar Pradesh. The rapid and unorganized development is forcing the city to face water scarcity in next few decades.
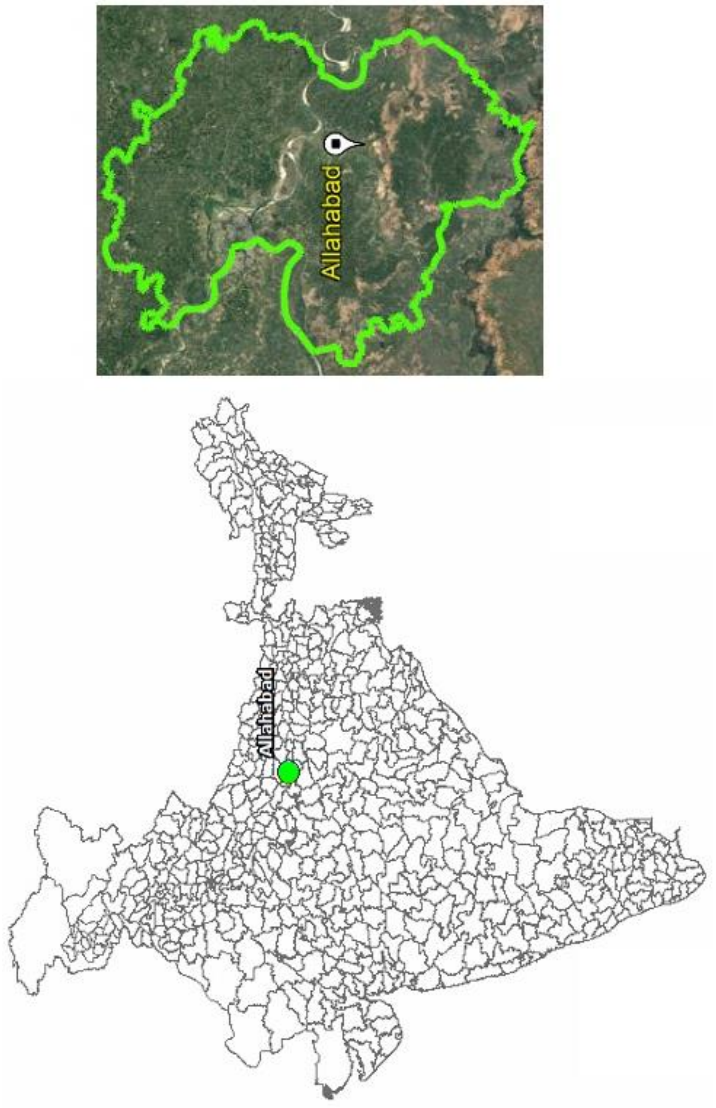

Figure 1. Study Area: Allahabad district (India)

\section{METHODOLOGY}

GRACE based datasets are available as $1^{\circ} \times 1^{\circ}$ grids in ASCII format for the whole world coordinates. Each grid value is the mid-point of average of grid values over the grid, then these grids are masked with the coordinates binding the study area. The purpose of masking is to remove the unwanted data present in the study area and to keep the regular grid shape just over the region of interest.

GRACE data of various versions from JPL, which can be downloaded from grace.jpl.nasa.gov website. To detect monthly changes in groundwater reserves using GRACE, a basic law equation has been developed that describes the components of TWS (Skaskevych et al., 2020):

$$
\Delta T W S=\Delta G W+\Delta S M+\Delta S W+\Delta S W E
$$

where $\triangle T W S$ is change in Terrestrial water storage; $\Delta G W$ is change in groundwater data; $\triangle S M$ is change in soil moisture data; $\Delta S W$ is change in surface water data; $\triangle S W E$ is change in snow water equivalent. Assuming $\Delta S W$ to be negligible for area where no surface water body exist, then the above equation can be further written as:

$$
\Delta G W=\Delta T W S-(\Delta S M+\Delta S W E)
$$

The TWS data comes from GRACE data set while SM data is obtained from GLDAS. These terms are generally expressed in volume $(\mathrm{km} 3)$ or mm of equivalent water height.

A practical analysis of changes in groundwater is carried out using a set of tools which is GRAMAT toolbox (Feng, 2019). It generally focuses on analyzing noise reduction techniques for processing spherical harmonic products of permitting data. The GRAMAT toolbox provides various destripping methods to reduce the errors in the form of noise and to remove the north to south stripes in the GRACE result coefficients. The data used is found on the grace tellus website (https//:jpl.nasa.gov.in) for the year 2002-2015 by using the GRAMAT toolbox and destripping method proposed by Chamber 2007 was used (see Swenson et al. 2008).

In first step of GRAMAT, initially, we have to provide the GRACE level-2 data files as input with removing degree 1 and degree 2 harmonic coefficients (Figure 2). For elimination of gravity field correlated error, there are various destripping methods available, therefore, we select the destripping method and removal of GIA signal. In addition to this, we are required to provide Gaussian filter radius for noise reduction in data, the radius might be a few of hundreds kilometre. Further, we complete output settings by providing location of output directory to save estimated spherical harmonic coefficients followed by maximum degree to show the trend map. Then, we provide location of control files to be saved which is used in further steps.

In second step, the output of the first step (sphere harmonic coefficients) is converted in required spatial resolution (1 degree or 0.25 degree) and a grid file is generated (Figure 3 ). In third step, generated grid file is used as input with boundary file of the study area in .bln format (Figure 4). Further, we provide location of output file and the time-series of mass variation for the study is generated. The fourth step consists of harmonic analysis of generated time-series results in both spatial and temporal manner (Figure 5). 


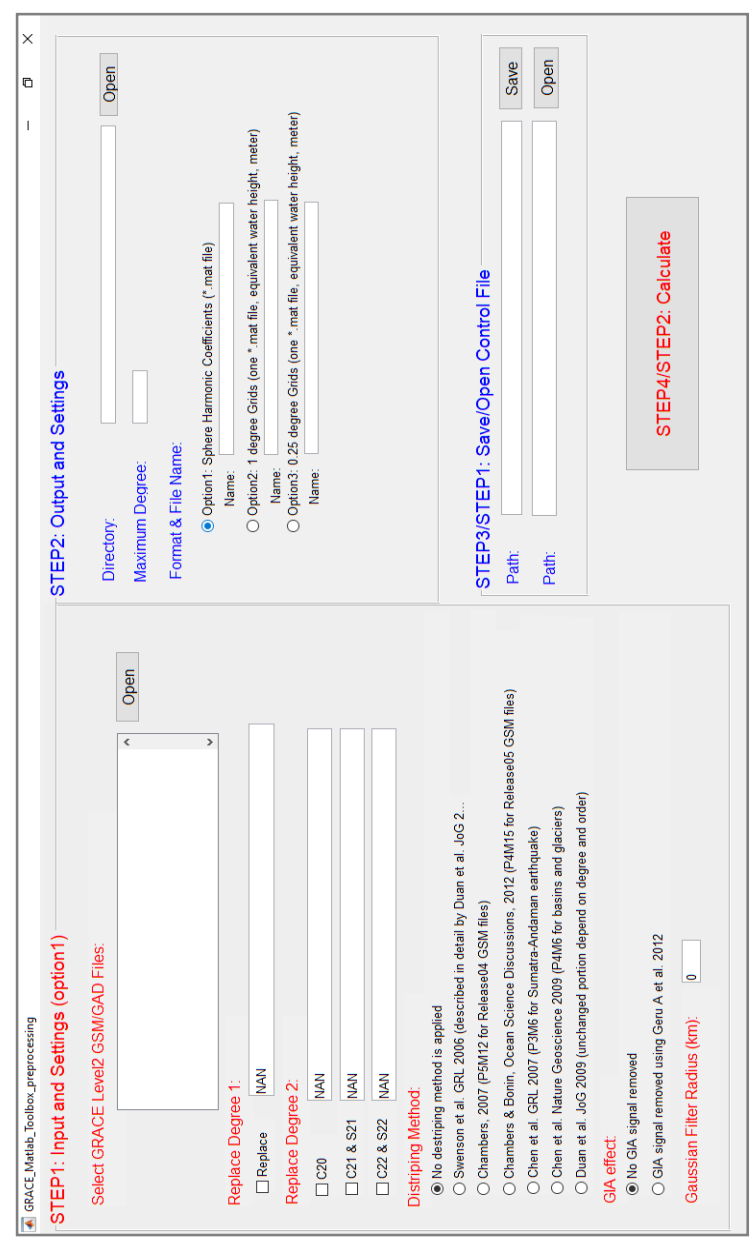

Figure 2. First step in GRAMAT toolbox: Generation of Spherical Harmonic Coefficients

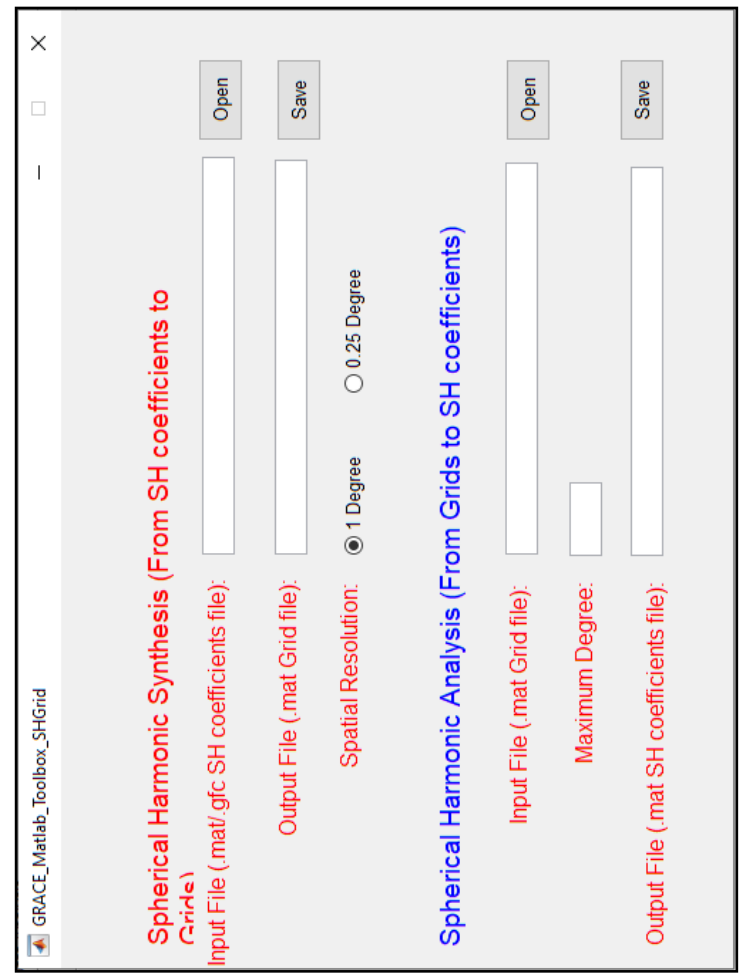

Figure 3. Second step in GRAMAT toolbox: Grid file generation of required spatial resolution

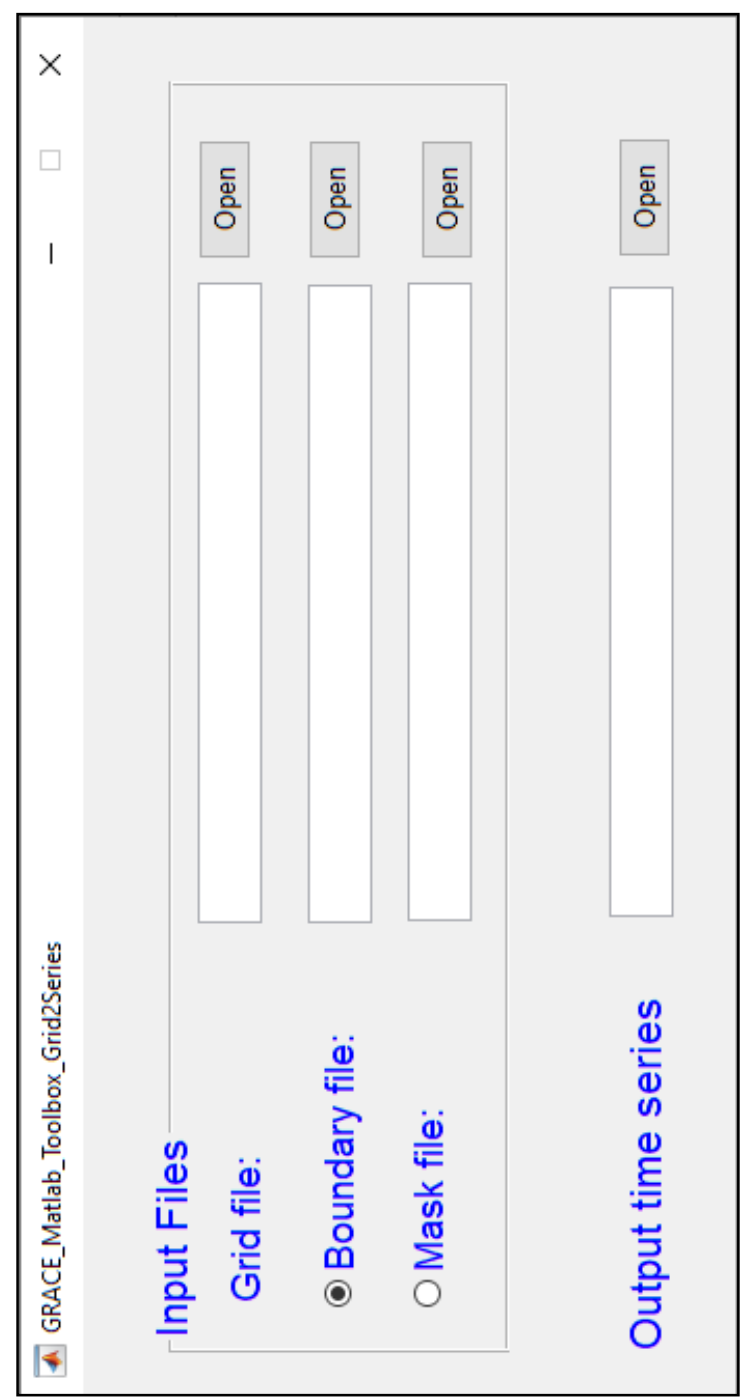

Figure 4. Third step in GRAMAT toolbox: Generation of timeseries of mass variation

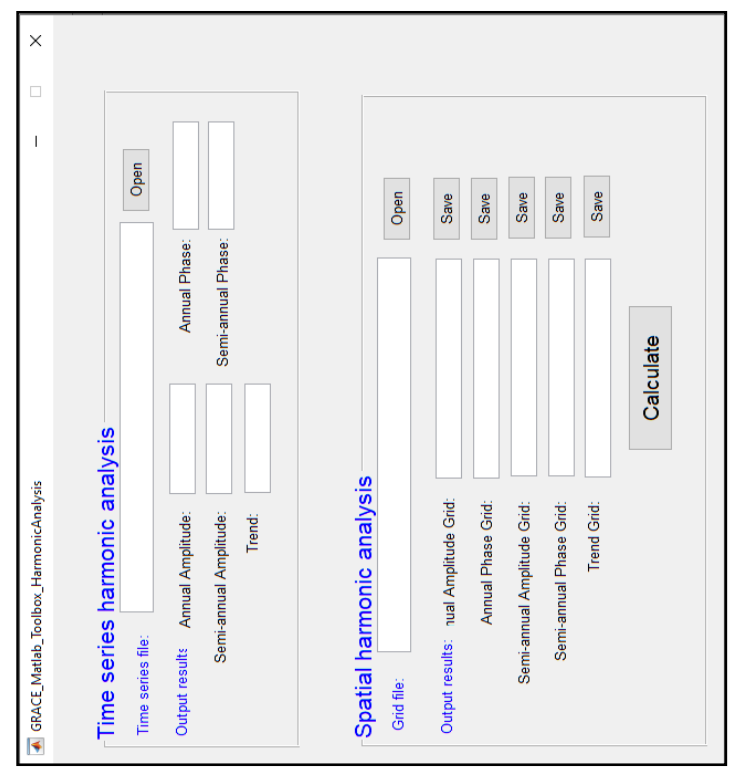

Figure 5. Fourth step in GRAMAT toolbox: Analysis of Generation of time-series results 


\section{RESULTS AND DISCUSSION}

This section includes time series graphs and trend maps for Allahabad region and hence we can see the variation present in the form of EWH (equivalent water height) in $\mathrm{cm}$. The obtained time-series of EWH for Allahabad region covering 2002-2015 is shown in Figure 6. From the results, we can see the periodic changes occurred in the sequential years. Additionally, we see that the equivalent water height thickness is reducing regularly from the year 2002 to 2015 and with reference to this trend of time series plot for further years so we can say the situation becomes very worse.

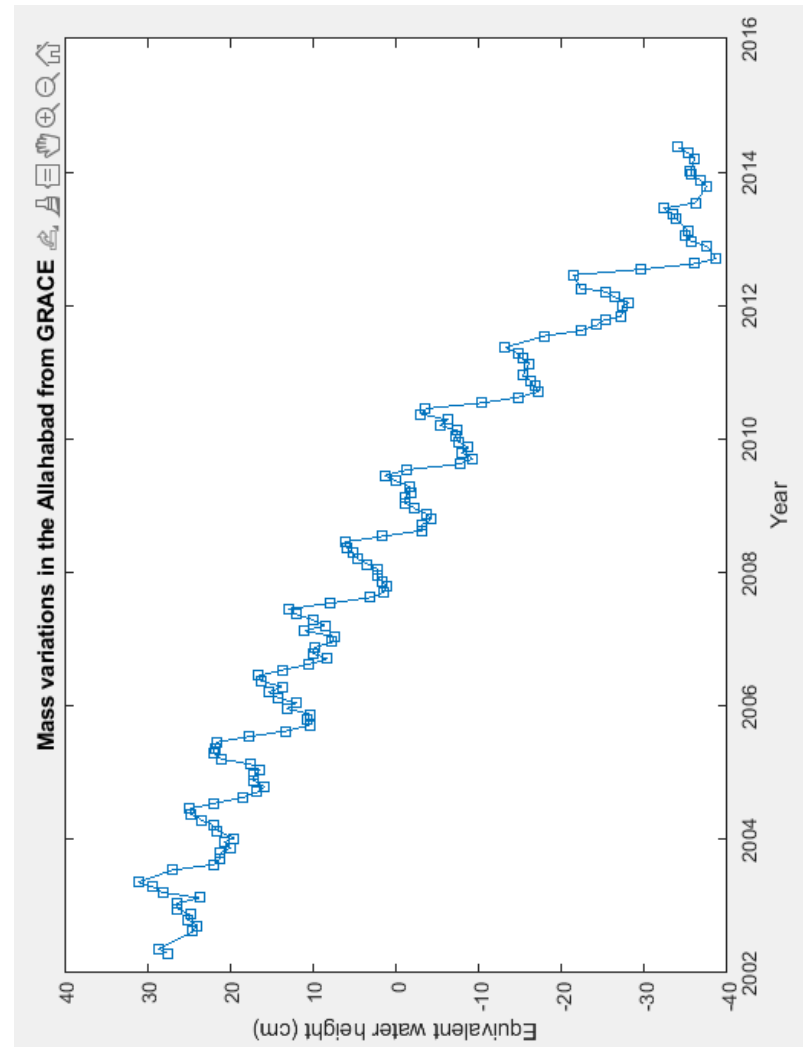

Figure 6. Time series of EWH for Allahabad region from 20022015

As a solution of this problem, we are required to identify areas where water level has to be recharged easily. Therefore, we have to use groundwater recharging techniques to conquer the problem such as through induced recharge methods, artificial injecting methods, flooding method, artificial channel method or Basin method. Construction of injection pits of required sizes corresponding to the area of water recharge should be prepared near the recharging area.

Figure 7 displays world trend map of mass variation from GRACE for 2002-2015. The red zone in the plot indicates the regions of water scarcities whereas the blue zone indicates the regions of water availability. From the world trend map, we can observe the current status of water availability among the world which is getting worse. As a result, scarcity of water and rapid increase in depletion of groundwater is observed.

As a solution of this problem, we are required to identify areas where water level has to be recharged easily. Therefore, we have to use groundwater recharging techniques to conquer the problem such as through induced recharge methods, artificial injecting methods, flooding method, artificial channel method or Basin method. Construction of injection pits of required sizes corresponding to the area of water recharge should be prepared near the recharging area.

Figure 7 displays world trend map of mass variation from GRACE for 2002-2015. The red zone in the plot indicates the regions of water scarcities whereas the blue zone indicates the regions of water availability. From the world trend map, we can observe the current status of water availability among the world which is getting worse. As a result, scarcity of water and rapid increase in depletion of groundwater is observed.

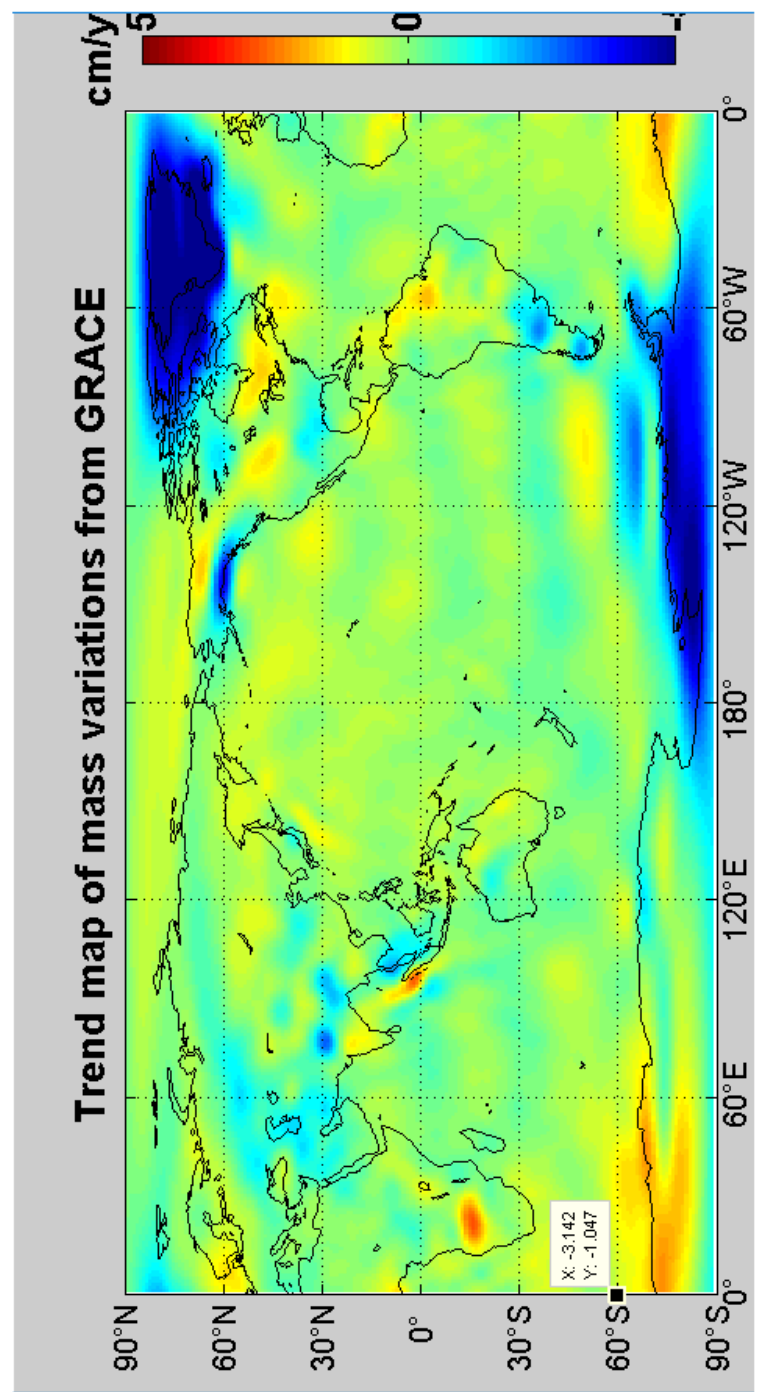

Figure 7. Trend map of mass variation from GRACE covering 2002-2015

\section{CONCLUSIONS}

In this paper, we present a GRACE Matlab Toolbox (GRAMAT) to process GRACE level-2 data and estimate spatio-temporal mass variations. A case study on TWS variations in the Allahabad region based on the GRACE data and the GRAMAT indicate a decreasing trend in EWH from 2002-2015 which shows the Allahabad city is heading towards water scarcity in next few decades. 


\section{REFERENCES}

Almeida, F. G. V. D., Calmant, S., Seyler, F., Ramillien, G., Blitzkow, D., Matos, A. C. C., Silva, J. S., 2012. Time variations of equivalent water heights' from Grace Mission and in-situ river stages in the Amazon basin. Acta Amazonica, 42(1), 125-134. doi.org/10.1590/S004459672012000100015.

Becker, M. W., 2006. Potential for satellite remote sensing of ground water. Groundwater, 44(2), 306-318. doi.org/10.1111/j.1745-6584.2005.00123.x.

Bhanja, S. N., Mukherjee, A., Saha, D., Velicogna, I., Famiglietti, J. S., 2016. Validation of GRACE based groundwater storage anomaly using in-situ groundwater level measurements in India. Journal of Hydrology, 543, 729-738. doi.org/10.1016/j.jhydrol.2016.10.042.

Chen, J. L., Wilson, C. R., \& Tapley, B. D. (2010). The 2009 exceptional Amazon flood and interannual terrestrial water storage change observed by GRACE. Water Resources Research, 46(12). doi.org/10.1029/2010WR009383

Chen, J., Famigliett, J. S., Scanlon, B. R., Rodell, M., 2016. Groundwater storage changes: present status from GRACE observations. Surveys in Geophysics, 37(2), 397-417. doi.org/10.1007/s10712-015-9332-4.

Chen, H., Zhang, W., Nie, N., Guo, Y., 2019. Long-term groundwater storage variations estimated in the Songhua River Basin by using GRACE products, land surface models, and insitu observations. Science of the Total Environment, 649, 372387. doi.org/10.1016/j.scitotenv.2018.08.352.

Jiang, D., Wang, J., Huang, Y., Zhou, K., Ding, X., Fu, J., 2014. The review of GRACE data applications in terrestrial hydrology monitoring. Advances in Meteorology, 2014.

Feng, W., 2019. GRAMAT: a comprehensive Matlab toolbox for estimating global mass variations from GRACE satellite data. Earth Science Informatics, 12(3), 389-404. doi.org/10.1007/s12145-018-0368-0.

Houborg, R., Rodell, M., Li, B., Reichle, R., \& Zaitchik, B. F., 2012. Drought indicators based on model-assimilated Gravity Recovery and Climate Experiment (GRACE) terrestrial water storage observations. Water Resources Research,48(7). doi.org/10.1029/2011WR011291.

Jiang, D., Wang, J., Huang, Y., Zhou, K., Ding, X., \& Fu, J., 2014. The review of GRACE data applications in terrestrial hydrology monitoring. Advances in Meteorology, 2014. doi.org/10.1155/2014/725131.

Landerer, F. W., \& Swenson, S. C., 2012. Accuracy of scaled GRACE terrestrial water storage estimates. Water resources research, 48(4). doi.org/10.1029/2011WR011453.

Rodell, M., Famiglietti, J. S., 2002. The potential for satellitebased monitoring of groundwater storage changes using GRACE: the High Plains aquifer, Central US. Journal of
Hydrology, 263(1-4), 245-256. doi.org/10.1016/S00221694(02)00060-4.

Rodell, M., Velicogna, I., \& Famiglietti, J. S., 2009. Satellitebased estimates of groundwater depletion in India. Nature, 460(7258), 999-1002. doi.org/10.1038/nature08238.

Singh, L., Saravanan, S., 2020. Satellite-derived GRACE groundwater storage variation in complex aquifer system in India. Sustainable Water Resources Management, 6, 1-15. doi.org/10.1007/s40899-020-00399-3.

Skaskevych, A., 2014. A comparison study of Grace-based groundwater modeling for data-rich and data-scarce regions (Doctoral dissertation).

Skaskevych, A., Lee, J., Jung, H. C., Bolten, J., David, J. L., Policelli, F. S., ... Ichoku, C. M., 2020. Application of GRACE to the estimation of groundwater storage change in a data-poor region: A case study of Ngadda catchment in the Lake Chad Basin. Hydrological Processes, 34(4), 941-955. doi.org/10.1002/hyp.13613.

Strassberg, G., Scanlon, B. R., Rodell, M., 2007. Comparison of seasonal terrestrial water storage variations from GRACE with groundwater-level measurements from the High Plains Aquifer (USA). Geophysical Research Letters, 34(14). doi.org/10.1029/2007GL030139.

Swenson, S., Chambers, D., \& Wahr, J., 2008. Estimating geocenter variations from a combination of GRACE and ocean model output. Journal of Geophysical Research: Solid Earth, 113(B8). doi.org/10.1029/2007JB005338.

Swenson, S., Yeh, P. J. F., Wahr, J., Famiglietti, J., 2006. A comparison of terrestrial water storage variations from GRACE with in situ measurements from Illinois. Geophysical Research Letters, 33(16). doi.org/10.1029/2006GL026962.

Syed, T. H., Famiglietti, J. S., Rodell, M., Chen, J., Wilson, C. R., 2008. Analysis of terrestrial water storage changes from GRACE and GLDAS. Water Resources Research, 44(2). doi.org/10.1029/2006WR005779.

Tapley, B. D., Bettadpur, S., Watkins, M., \& Reigber, C. (2004). The gravity recovery and climate experiment: Mission overview and early results. Geophysical Research Letters, 31(9). doi.org/10.1029/2004GL019920.

Tapley, B. D., Bettadpur, S., Ries, J. C., Thompson, P. F., \& Watkins, M. M., 2004. GRACE measurements of mass variability in the Earth system. Science, 305(5683), 503-505.

Tian, S., Tregoning, P., Renzullo, L. J., van Dijk, A. I., Walker, J. P., Pauwels, V. R., \& Allgeyer, S., 2017. Improved water balance component estimates through joint assimilation of GRACE water storage and SMOS soil moisture retrievals. Water Resources Research,53(3), 1820-1840. doi.org/10.1002/2016WR019641. 
Yeh, P. J. F., Swenson, S. C., Famiglietti, J. S., Rodell, M. 2006. Remote sensing of groundwater storage changes in Illinois using the Gravity Recovery and Climate Experiment (GRACE). Water Resources Research, 42(12). doi.org/10.1029/2006WR005374.

Wahr, J., Swenson, S., Velicogna, I., 2006. Accuracy of GRACE mass estimates. Geophysical Research Letters, 33(6). doi.org/10.1029/2005GL025305.

Wang, H., Jia, L., Steffen, H., Wu, P., Jiang, L., Hsu, H., ... Hu, B., 2013. Increased water storage in North America and Scandinavia from GRACE gravity data. Nature Geoscience, 6(1), 38-42. doi.org/10.1038/ngeo1652.

Wouters, B., Bonin, J. A., Chambers, D. P., Riva, R. E., Sasgen, I., \& Wahr, J., 2014. GRACE, time-varying gravity, Earth system dynamics and climate change. Reports on Progress in Physics, 77(11), 116801. doi.org/10.1088/00344885/77/11/116801. 